\title{
Early versus late initiation of GH replacement in adult-onset hypopituitarism
}

\author{
Mark R Postma ${ }^{1}$, Pia Burman² and André P van Beek ${ }^{1}$ \\ 'Department of Endocrinology, University Medical Center Groningen, University of Groningen, Groningen, The Netherlands \\ 2Department of Endocrinology, Skane University Hospital Malmö, University of Lund, Lund, Sweden \\ Correspondence should be addressed to A P van Beek: a.p.van.beek@umcg.nl
}

\begin{abstract}
Introduction: Adult-onset growth hormone deficiency (AGHD) is usually the last deficiency to be substituted in hypopituitarism. In children with documented GH deficiency, treatment without delay is crucial for achieving optimal effects on growth and development. In adults, it is not known whether a delay in treatment initiation influences biochemical response and the favourable physiological effects resulting from GH replacement therapy (GHRT).

Methods: A total of $1085 \mathrm{GH}$-deficient adults from KIMS (Pfizer International Metabolic Database) were included, adequately replaced with all pituitary hormones except for $\mathrm{GH}$ at baseline. Patients were stratified by sex and age (20-50 years and $\geq 50$ years) and subsequently divided into two groups below and above the median duration of unsubstituted AGHD for that subgroup. The median time of unsubstituted GHD for the total cohort was 2.53 years $(\mathrm{P} 5=0.35, \mathrm{P} 95=24.42$ ).

Results: Beneficial effects of 4 years of GHRT were observed on lipids and quality of life in all subgroups. A decrease in waist circumference was observed only in older ( $>50$ years) patients. There was no difference in IGF-I SDS and in GH dose required to normalize IGF-I in patients with a duration of unsubstituted AGHD above or below the median. No relevant differences were found between the groups for anthropometric measures, cardiovascular risk factors and quality of life scores.

Conclusion: In contrast to GHD in children and adolescents, no difference could be established in treatment response between early or late initiation of GHRT in AGHD in terms of required GH dose, IGF-I, metabolic health and quality of life.
\end{abstract}

\author{
Key Words \\ - adult-onset growth \\ hormone deficiency \\ - growth hormone \\ replacement therapy \\ - hypopituitarism \\ - treatment initiation
}

\section{Introduction}

Adult growth hormone deficiency (AGHD) is characterized by changes in body fat distribution with increased central adiposity, hyperlipidaemia, increased predisposition to atherogenesis and reduced bone remodelling activity. It is also associated with a reduced quality of life. AGHD is usually caused by pituitary adenomas, recently also termed pituitary neuroendocrine tumours (PitNETs) (1), or the consequences of treatment of these tumours, including surgery and/or irradiation. It therefore usually occurs in the context of additional features of hypopituitarism, compounding the clinical picture attributable to AGHD $(2,3)$. Available evidence shows benefit of GH replacement therapy (GHRT) on body composition, exercise capacity, bone health, several cardiovascular risk factors and quality of life $(3,4,5)$. Pitfalls of GH and IGF-I assays and the recent upward adjustment of the normative IGF-I SD scores for the iSYS IGF-I assay make early recognition of AGHD increasingly difficult $(6,7,8)$. It is not known whether these changes in SD scores and the likely association of delayed initiation of GHRT result in poorer outcomes.

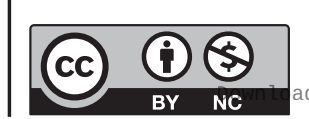

This work is licensed under a Creative Commons Attribution-NonCommercial 4.0 International License. ded from Bioscientifica.com at 04/26/2023 11:47:48AM 
In paediatric growth hormone therapy, it is well known that age of treatment onset is predictive of final height outcome (9). In addition, it has been shown that growth acceleration during the first year is more marked in younger children $(10,11)$. In adults, we and others previously demonstrated that age and sex influence body composition, both with respect to the effects of GHD (12, 13) and GHRT $(14,15)$.

Against this background, we studied whether there was a difference in response to GHRT between longer and shorter duration of unsubstituted AGHD in patients grouped by age and sex. We hypothesized that early initiation of GHRT in AGHD results in better responsiveness of the somatotrophic axis with higher increases in IGF-I, more favourable effects on metabolic health and better improvement of quality of life compared to late initiation.

\section{Methods}

\section{Study population}

The KIMS database (Pfizer International Metabolic Database) was used to study the effects of hypopituitarism on obesity. KIMS, initiated in 1994, is a pharmacoepidemiological multicentre survey of adult hypopituitary (GH deficient) patients treated with $\mathrm{GH}$ replacement therapy (Genotropin $\left.{ }^{\circledR}\right)$ (16). Included were all patients with a known duration of confirmed AGHD, defined as a peak GH level less than $3 \mu \mathrm{g} / \mathrm{L}$ mainly indicated by insulininduced hypoglycaemia (in 76\% of cases), but in other cases by a weaker GH stimulation test like the arginine (in $9 \%$ ), GHRH (in 6\%), glucagon (in 1\%), or other tests (in $8 \%$ ). Patients were adequately replaced with all pituitary hormones except for GH. Excluded were patients with a previous diagnosis of Cushing's disease, acromegaly and craniopharyngioma because these conditions are known to affect body composition, cardiovascular risk factors and quality of life. For similar reasons of confounding bias, females reported to be on oestrogen and females who got pregnant during the study time frame were excluded. Finally, patients exposed to radiotherapy (RT) and patients with unknown treatment for diagnoses in which RT is an option were excluded, as it was not possible to determine the exact duration of AGHD in these patients. The patient population consisted of patients with isolated AGHD as well as multiple pituitary hormone deficiencies. Patients included in this study started GH replacement therapy at entry into KIMS and were in follow-up for an average time of 4.0 years (s.D. 0.2 years). Patients who did not complete 4 years of follow-up were not included in the analyses.
With these criteria, a total of 1085 patients with hypopituitarism were identified for inclusion in the analysis. The KIMS countries (number of participants) for the present study were Argentina (12), Austria (19), Belgium (129), Switzerland (5), Czech Republic (31), Germany (304), Denmark (30), Spain (81), France (49) United Kingdom (97), Greece (7), Hungary (12), Ireland (12), Luxembourg (1), the Netherlands (81), Serbia (1), Sweden (184), Slovakia (9) and the United States (21).

Data were collected for KIMS at clinical visits on specially designed case record forms. The data collection process was externally monitored and audited. Demographic and clinical data related to pituitary and cardiovascular disease were used for the present analysis. The data collection into KIMS was approved by the Institutional Review Boards/Ethical Committees as required by local regulations in each participating country. Written informed consent was obtained from all patients before any data were entered into KIMS. The study was performed in accordance with The Declaration of Helsinki.

\section{Estimated duration of unsubstituted AGHD}

The estimated duration of unsubstituted AGHD was defined as time from the date of pituitary disease diagnosis as reported by local investigators to the date of entry into KIMS. In the rare event that the date of biochemical confirmation of AGHD was reported to be before the date of pituitary disease diagnosis, the date of biochemical confirmation was used. The median time of unsubstituted GHD for the total cohort was 2.53 years (P5 = 0.35, P95 = 24.42).

\section{Stratification and definitions}

Patients were stratified by sex and age (20-50 years and $\geq 50$ years) and subsequently divided into two groups below and above the median duration of unsubstituted AGHD for that subgroup. The age at which a patient entered KIMS was chosen for stratification. Thus, a complete data set together with anthropometric measures and laboratory determinations was guaranteed. A provisional diagnosis of diabetes was defined on a single fasting plasma glucose level of $7.0 \mathrm{mmol} / \mathrm{L}$ or higher according to the American Diabetes Association criteria (17) or the use of antidiabetic drugs. The Seventh Report of the Joint Committee on Prevention, Detection, Evaluation, and Treatment of High Blood Pressure (JNC 7) was used to define hypertension, i.e. a systolic blood pressure of more than $140 \mathrm{mmHg}$ or

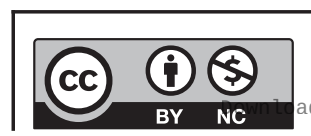

This work is licensed under a Creative Commons Attribution-NonCommercial 4.0 International License. ded from Bioscientifica.com at 04/26/2023 11:47:48AM 
a diastolic blood pressure more than $90 \mathrm{mmHg}$ or the use of antihypertensives (18).

\section{Anthropometric measures}

Height was measured with an accuracy of $0.5 \mathrm{~cm}$ and weight (in kilograms) to one decimal place. BMI was calculated from the formula: weight/height squared (kilograms per square meter). Waist circumference was measured in the supine position midway between the iliac crest and the lowest level of the thorax and hip as the maximal circumference. Blood pressure measurements in KIMS were standard office registrations.

\section{Laboratory measurements}

Measurements of serum total cholesterol (19), highdensity lipoprotein (HDL) cholesterol (20), and triglycerides (21) were performed by standard methods according to the KIMS protocol. Lipids were measured centrally and serum low-density lipoprotein (LDL) cholesterol was calculated using the Friedewald formula (22). Serum insulin-like growth factor I (IGF-I) was determined by RIA after acid/ethanol precipitation of IGF-binding proteins (Nichols Institute Diagnostics, San Juan Capistrano, CA, USA) until November 2002 and by chemiluminescence immunoassays from 2003 to 2004 (Nichols Advantage ${ }^{\circledR}$ System) and from 2005 to 2012 (Immulite 2500, DPC Siemens). For each assay, age- and gender-specific reference ranges were used to determine IGF-I SDS. Reference ranges and consistency of IGF-I SDS values between assays were validated internally. All above mentioned measurements were performed in a central laboratory. Glucose concentrations were measured in local participating centres. Whole blood concentrations were transformed to plasma values using an internally validated correction factor (23). All measurements including glucose were determined in fasting samples.

\section{Quality of life assessment}

Quality of life was assessed using the disease-specific Quality of Life Assessment of Growth Hormone Deficiency in Adults (QoL-AGHDA), a patient needs-based instrument developed specifically to detect deficits in areas that are affected in adults with GHD (24). The measure consists of 25 questions with 'yes' or 'no' response choices, with 'yes' answer indicating that the patient perceives a problem. The sum of 'yes' responses constitute a score, with a high score denoting a poor QoL. The QoL-AGHDA demonstrated satisfactory psychometric properties across a wide range of languages (25).

\section{Statistical analysis}

All calculations were performed with SAS (version 9.4, SAS Institute Inc.) or SPSS 22.0 (SPSS) software. Data are reported as mean \pm S.D. or proportion, depending on type of variable. Males and females were analysed separately to avoid potential confounding by sex. For assessment of significance of mean differences between the patients below vs above the median for duration of unsubstituted AGHD, unpaired Student's t-tests were performed. If variances were tested unequal between populations, Satterthwaite's correction was applied. Comparisons of proportions were performed using the $\mathrm{X}^{2}$ test. A two-sided $P$ value $<0.05$ was considered to be significant.

\section{Results}

\section{Baseline characteristics}

Baseline characteristics of the $\mathrm{GH}$ deficient patients are shown in Table 1 . The mean estimated duration of unsubstituted AGHD for the total cohort was 6.0 years (s.D. 8.2 years), of which 1.7 years (s.D. 3.8 years) were biochemically confirmed. The most prevalent diagnosis was pituitary adenoma. Most patients received surgery as primary treatment and had multiple other pituitary hormone deficiencies. ADH deficiency was less common in patients aged $>50$ years. Male patients had more ACTH and LH/FSH deficiency than females. Male patients with a duration of unsubstituted AGHD below the median received surgical treatment more often and had a significantly higher IGF-I SDS at baseline than those above the median. However, no difference was found between these groups in $\mathrm{GH}$ dose required to normalize IGF-I. Table 2 shows anthropometric measures, cardiovascular risk factors and quality of life scores for both sexes in the two age groups of patients at baseline.

\section{Adequacy of hormonal substitution}

Between 97 and 99\% of patients with TSH and ACTH deficiency received adequate hormonal substitution both at baseline and after 4 years of GHRT. More than 95\% of LH/FSH deficient males were treated with testosterone throughout this observational study. The prevalence of other pituitary deficiencies did not change after 4 years of GHRT (data not shown).

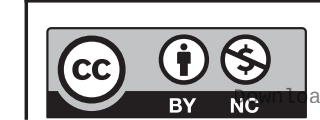


놋ㅇำ

\begin{tabular}{|c|c|c|c|c|c|c|c|}
\hline \multirow{2}{*}{ 옷 \& } & 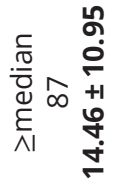 & 우ำ & nn & 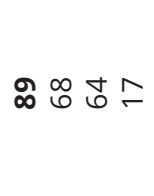 & 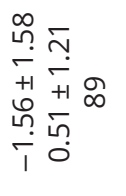 & 只 & 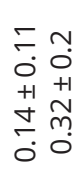 \\
\hline & 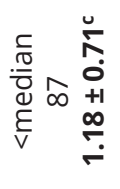 & 숭 $\infty 6$ ŏ & 뉴 & 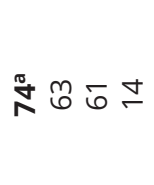 & 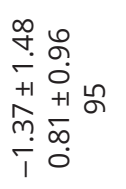 & g & 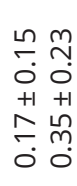 \\
\hline \multirow{2}{*}{ 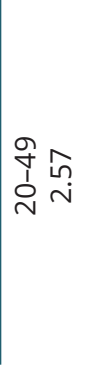 } & 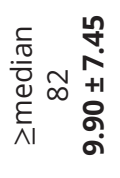 & 路ヘ요 & กิ & ㅇํํํ & 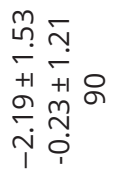 & ำกำ & 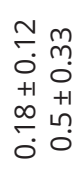 \\
\hline & 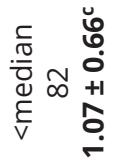 & :్రి & $\hat{m}$ & ำ ํํำ & 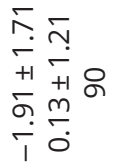 & ஜூ & 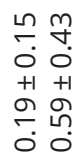 \\
\hline \multirow{2}{*}{ 옷 늄 } & 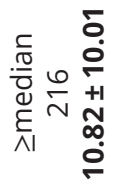 & 묨 & $m$ & হঃ ু ニ & 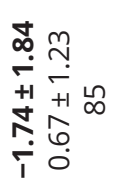 & 守 & 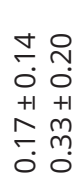 \\
\hline & 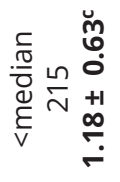 & வ & $\stackrel{\infty}{\infty}$ & ํํㅅ ら & 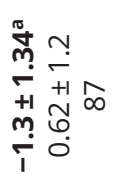 & f & 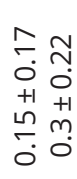 \\
\hline \multirow{2}{*}{$\begin{array}{l}\stackrel{9}{1} \\
\stackrel{\sim}{\sim} \\
\stackrel{n}{N}\end{array}$} & 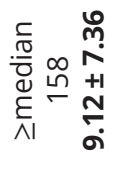 & 只 ${ }^{\infty} \wedge N \stackrel{\infty}{\circ}$ & 누 & ミホ ু゙ & 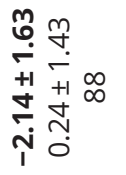 & nn & $\begin{array}{ll}\bar{T} & 0 \\
0 & 0 \\
+1 & 0 \\
\infty & +1 \\
\leftarrow & 0\end{array}$ \\
\hline & 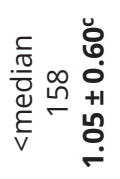 & 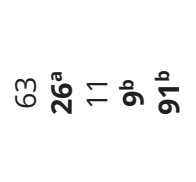 & : & 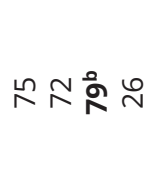 & 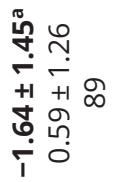 & $\bar{n}$ & 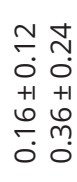 \\
\hline
\end{tabular}
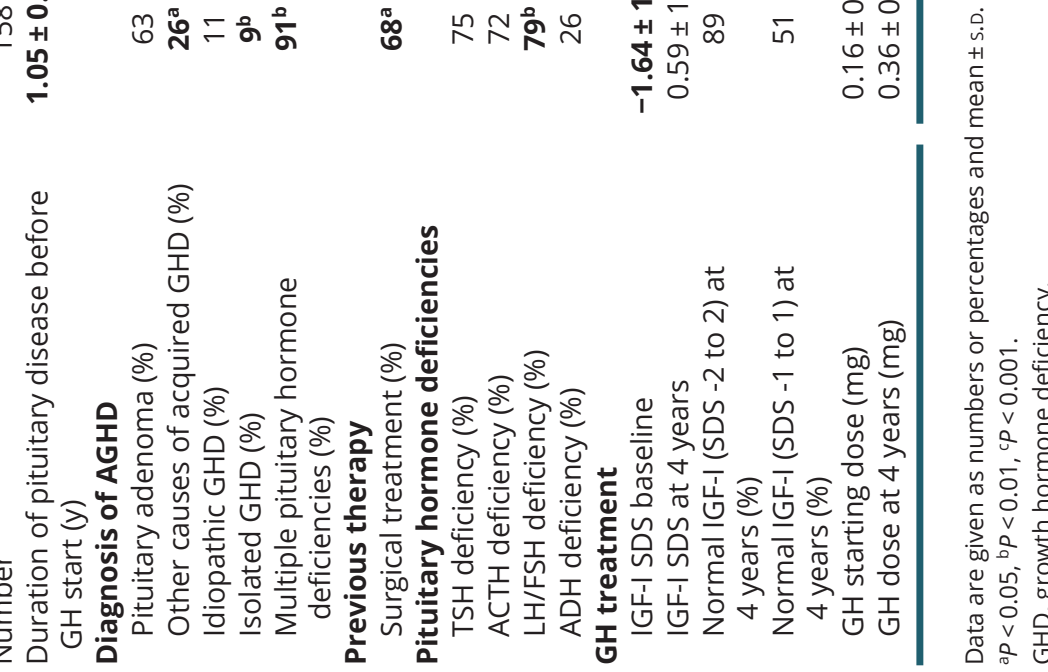


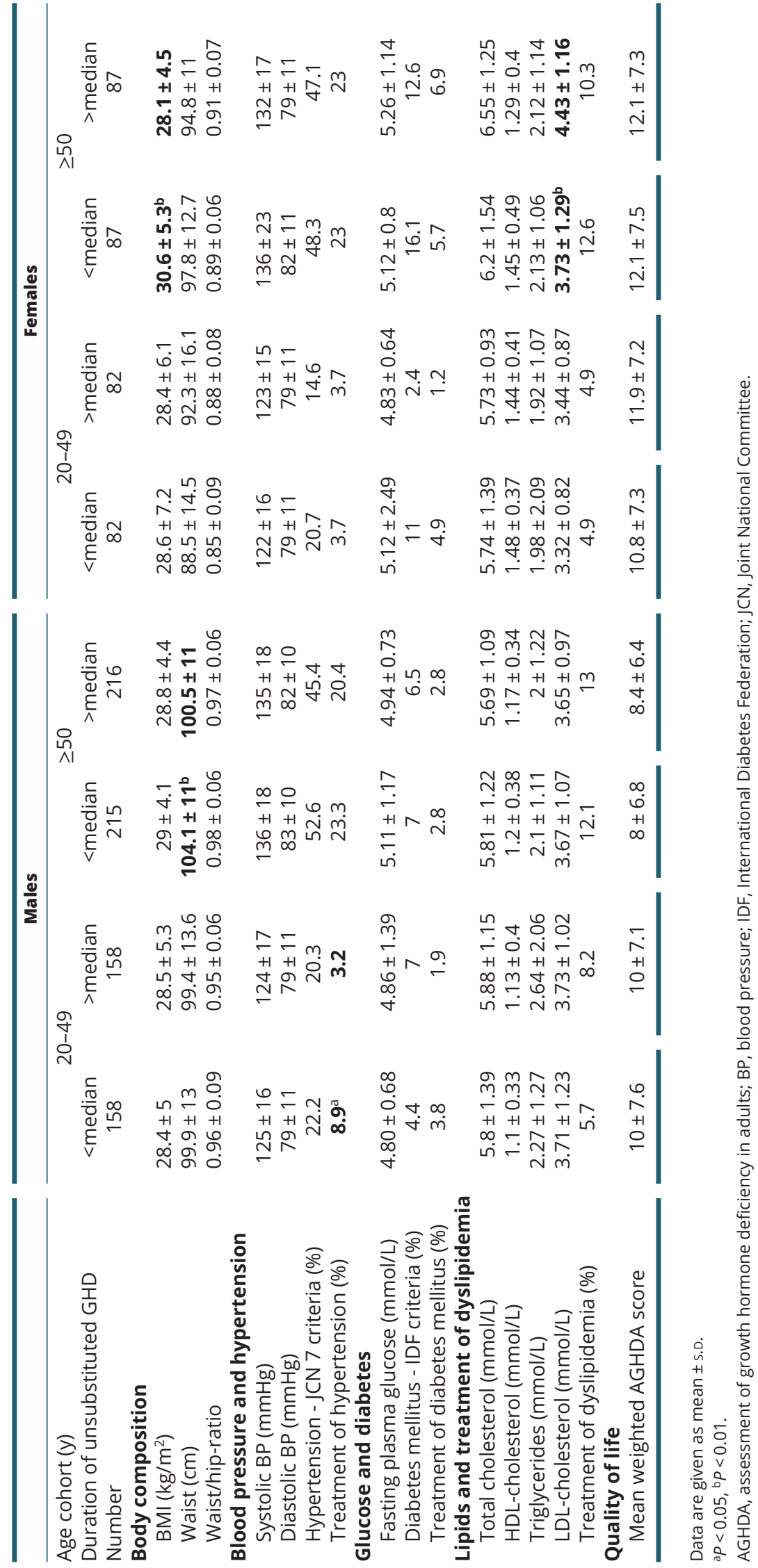




\section{Effects of 4 years of GHRT}

Beneficial effects of 4 years of GHRT were observed on lipids and quality of life in all subgroups. A decrease in waist circumference was observed only in older $(>50$ years) patients. Changes in those measures after 4 years of GHRT are shown in Table 3.

\section{Effects of early versus late initiation of GHRT}

There was no difference in GH dose required to normalize IGF-I in patients with a duration of unsubstituted AGHD above or below the median. Additionally, IGF-I SDS did not differ between the early and late initiation groups after 4 years of GHRT.

\section{Discussion}

In this study, we investigated the effects of early versus late initiation of GHRT in adults with respect to GH dose, IGF-I, quality of life and metabolic health. Patients were grouped by age and sex, which are confounders known to influence the somatotrophic axis $(12,13)$. Four years of GHRT resulted in beneficial effects on lipids and quality of life in all cohorts. A decrease in waist circumference was observed only in the group of patients above 50 years of age. No differences were observed in GH dose required to normalize IGF-I between the groups with a duration of unsubstituted AGHD above or below the median. Additionally, IGF-I SDS did not differ between the groups after 4 years of GHRT. No relevant differences were found between the groups for anthropometric measures, cardiovascular risk factors and quality of life scores.

Our results are reassuring in relation to current clinical practice, in which AGHD is usually the last deficiency to be substituted in hypopituitarism. However, they are in contrast to the effects of paediatric growth hormone therapy, in which age of treatment onset is predictive of both growth acceleration during the first year and final height outcome (9). However, growth velocity in children is dependent on more hormonal and anabolic influences than GH per se, such as tempo of puberty and nutritional status.

For the initiation of postmenopausal oestradiol replacement therapy (ERT), it is now generally accepted that timing is critical; the sooner oestrogen is started after menopause, the greater the benefits $(26,27)$. These findings are presumed to be related to the health of the underlying tissue and/or to other factors such as downregulation of receptors $(28,29)$. Whether a similar mechanism could be present in AGHD has not previously been addressed. Serum GH and IGF-I decrease with age, peaking at late adolescence and declining from age 20 , resulting in considerably lower levels after age 60 . This is likely to be the consequence of impaired signal transduction within the somatotrophic axis with age (30, 31). However, the results of this study indicate that the timing hypothesis does not apply to the somatotrophic axis, as late initiation of GHRT in AGHD did not result in less responsiveness. Oestradiol is a steroid hormone binding primarily to oestrogen receptors, nuclear proteins that bind to DNA and control gene expression, whereas $\mathrm{GH}$ binds to the membrane-bound $\mathrm{GH}$ receptor, activating several intra- and intercellular signal transduction pathways (32). The regulation of these different classes of receptors is inherently different and may contribute to the different findings.

Our study is prone to several shortcomings. First, the estimated duration of unsubstituted AGHD was defined as time from the date of pituitary disease diagnosis as reported by local investigators to the date of entry into KIMS. In the rare event that the date of biochemical confirmation of AGHD was reported to be before the date of pituitary disease diagnosis, the date of biochemical confirmation was used. Both definitions are proxies, but the date of biochemical confirmation is most often an underestimation of the actual duration of unsubstituted AGHD. Although the use of the date of pituitary disease diagnosis as starting point likely results in an overestimation of the actual duration of unsubstituted AGHD, the large contrast between short and long duration of unsubstituted AGHD as reported in this study is crucial to its analysis and provides a solid basis for its conclusions. Although dates of pituitary disease diagnosis were entered retrospectively at entry into KIMS, they were based on medical records and checked by a monitor, reducing the risk of obtaining incorrect information.

Secondly, although appropriate for a large epidemiological study, the use of BMI and waist circumference alone is not optimal to characterize body composition. Data on fat mass, fat-free mass, and bone mass are, however, not available in KIMS. Thirdly, a selection bias may be present by the exclusion of patients with co-morbidities and diabetes, although in recent years more patients with co-morbidities and diabetes were considered for $\mathrm{GH}$ replacement therapy, possibly reflecting increased knowledge and confidence in $\mathrm{GH}$ therapy gained with time (33).
This work is licensed under a Creative Commons Attribution-NonCommercial 4.0 International License. ded from Bioscientifica.com at 04/26/2023 11:47:48AM via free access 


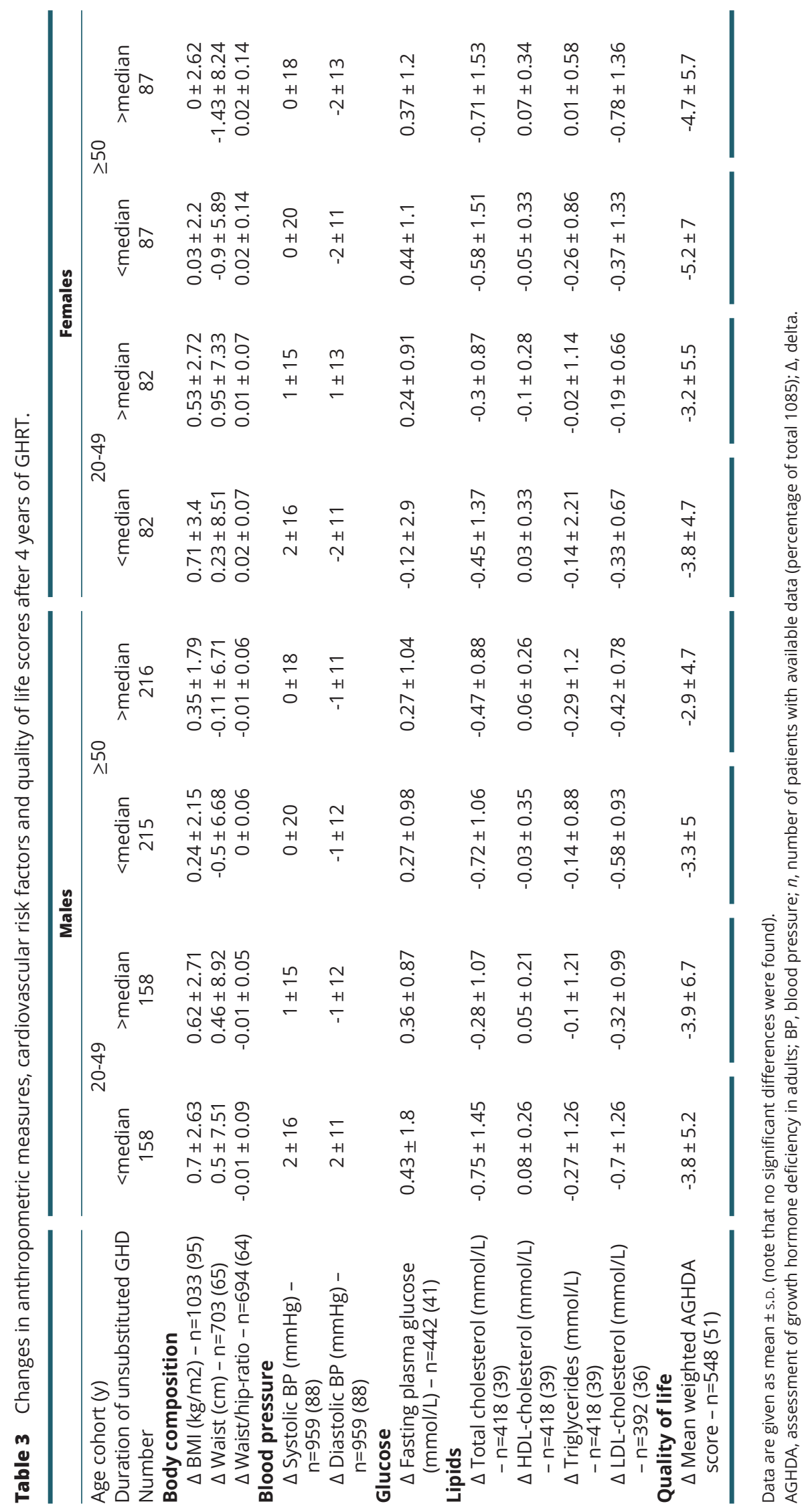


Finally, one could argue that male patients below the median for duration of unsubstituted GHD receiving surgical treatment more often constitutes confounding by indication, as patients who receive surgical treatment are generally in follow-up according to protocol, are tested for hypopituitarism regularly and therefore have a higher chance to get GHRT early. However, this potential bias did not result in a difference between these groups in $\mathrm{GH}$ dose required to normalize IGF-I, nor in a difference in treatment response.

In conclusion, in contrast to GHD in children and adolescents, no difference could be established in treatment response between early or late initiation of GHRT in AGHD in terms of required GH dose, IGF-I, metabolic health and quality of life.

\section{Declaration of interest}

The authors declare that there is no conflict of interest that could be perceived as prejudicing the impartiality of the research reported.

\section{Funding}

$M R P$ is a recipient of the Pfizer ASPIRE Young Investigator Research Awards in Endocrinology. P B and A P v B are members of the KIMS Steering Committee and have received consulting fees from Pfizer.

\section{Acknowledgements}

The authors express their thanks to the KIMS investigators in general and to Anders F Mattsson in particular, who provided the patient data. KIMS is sponsored by Pfizer.

\section{References}

1 Asa SL, Casar-Borota O, Chanson P, Delgrange E, Earls P, Ezzat S, Grossman A, Ikeda H, Inoshita N, Karavitaki N, et al. From pituitary adenoma to pituitary neuroendocrine tumor (PitNET): an International Pituitary Pathology Club proposal. Endocrine-Related Cancer 24 C5-C8. (https://doi.org/10.1530/ERC-17-0004)

2 Feldt-Rasmussen U \& Klose M. Adult growth hormone deficiency clinical management. Endotext. South Dartmouth, MA, USA: MDText. com, Inc., 2017. (available at: https://www.ncbi.nlm.nih.gov/books/ NBK425701/)

3 Molitch ME, Clemmons DR, Malozowski S, Merriam GR, Vance ML \& Endocrine Society. Evaluation and treatment of adult growth hormone deficiency: an Endocrine Society clinical practice guideline. Journal of Clinical Endocrinology and Metabolism 201196 1587-1609. (https://doi.org/10.1210/jc.2011-0179)

4 Bollerslev J, Ueland T, Jorgensen AP, Fougner KJ, Wergeland R, Schreiner T \& Burman P. Positive effects of a physiological dose of GH on markers of atherogenesis: a placebo-controlled study in patients with adult-onset GH deficiency. European Journal of Endocrinology $2006 \mathbf{1 5 4} 537-543$. (https://doi.org/10.1530/ eje.1.02125)

5 Hazem A, Elamin MB, Bancos I, Malaga G, Prutsky G, Domecq JP, Elraiyah TA, Abu Elnour NO, Prevost Y, Almandoz JP, et al. Body composition and quality of life in adults treated with GH therapy: a systematic review and meta-analysis. European Journal of Endocrinology 2012166 13-20. (https://doi.org/10.1530/EJE-11-0558)

6 Junnila RK, Strasburger CJ \& Bidlingmaier M. Pitfalls of insulinlike growth factor-I and growth hormone assays. Endocrinology and Metabolism Clinics of North America 201544 27-34. (https://doi. org/10.1016/j.ecl.2014.10.003)

7 Bidlingmaier M, Friedrich N, Emeny RT, Spranger J, Wolthers OD, Roswall J, Korner A, Obermayer-Pietsch B, Hubener C, Dahlgren J, et al. Reference intervals for insulin-like growth factor-1 (IGF-I) from birth to senescence: results from a multicenter study using a new automated chemiluminescence IGF-I immunoassay conforming to recent international recommendations. Journal of Clinical Endocrinology and Metabolism 201499 1712-1721. (https://doi. org/10.1210/jc.2013-3059)

8 Varewijck AJ, Lamberts SW, van der Lely AJ, Neggers SJ, Hofland LJ \& Janssen JA. The introduction of the IDS-iSYS total IGF-1 assay may have far-reaching consequences for diagnosis and treatment of GH deficiency. Journal of Clinical Endocrinology and Metabolism 2015100 309-316. (https://doi.org/10.1210/jc.2014-2558)

9 Wit JM, Deeb A, Bin-Abbas B, Al Mutair A, Koledova E \& Savage MO. Achieving optimal short- and long-term responses to paediatric growth hormone therapy. Journal of Clinical Research in Pediatric Endocrinology 201911 329-340. (https://doi.org/10.4274/jcrpe. galenos.2019.2019.0088)

10 Ranke MB, Lindberg A, Chatelain P, Wilton P, Cutfield W, AlbertssonWikland K \& Price DA. Derivation and validation of a mathematical model for predicting the response to exogenous recombinant human growth hormone $(\mathrm{GH})$ in prepubertal children with idiopathic $\mathrm{GH}$ deficiency. KIGS International Board. Kabi Pharmacia International Growth Study. Journal of Clinical Endocrinology and Metabolism 1999 84 1174-1183. (https://doi.org/10.1210/jcem.84.4.5634)

11 Ranke MB, Lindberg A, Price DA, Darendeliler F, AlbertssonWikland K, Wilton P, Reiter EO \& KIGS International Board. Age at growth hormone therapy start and first-year responsiveness to growth hormone are major determinants of height outcome in idiopathic short stature. Hormone Research 200768 53-62. (https:// doi.org/10.1159/000098707)

12 Pijl H, Langendonk JG, Burggraaf J, Frolich M, Cohen AF, Veldhuis JD $\&$ Meinders AE. Altered neuroregulation of GH secretion in viscerally obese premenopausal women. Journal of Clinical Endocrinology and Metabolism 200186 5509-5515. (https://doi.org/10.1210/ jcem.86.11.8061)

13 van Beek AP, Wolffenbuttel BH, Runge E, Trainer PJ, Jonsson PJ \& Koltowska-Haggstrom $\mathrm{M}$. The pituitary gland and age-dependent regulation of body composition. Journal of Clinical Endocrinology and Metabolism 201095 3664-3674. (https://doi.org/10.1210/jc.20092506)

14 Burman P, Johansson AG, Siegbahn A, Vessby B \& Karlsson FA. Growth hormone $(\mathrm{GH})$-deficient men are more responsive to $\mathrm{GH}$ replacement therapy than women. Journal of Clinical Endocrinology and Metabolism 199782 550-555. (https://doi.org/10.1210/jcem.82.2.3776)

15 Postma MR, van Beek AP, Jonsson PJ, van Bunderen CC, Drent ML, Mattsson AF \& Camacho-Hubner C. Improvements in body composition after 4 years of growth hormone treatment in adult-onset hypopituitarism compared to age-matched controls. Neuroendocrinology 2019109 131-140. (https://doi. org/10.1159/000499430)

16 Abs R, Bengtsson BA, Hernberg-Stahl E, Monson JP, Tauber JP, Wilton P \& Wüster C. GH replacement in 1034 growth hormone deficient hypopituitary adults: demographic and clinical characteristics, dosing and safety. Clinical Endocrinology 199950 703-713. (https://doi.org/10.1046/j.1365-2265.1999.00695.x)

17 Expert Committee on the Diagnosis and Classification of Diabetes Mellitus. Report of the expert committee on the diagnosis and classification of diabetes mellitus. Diabetes Care 200326 (Supplement 1) S5-S20. (https://doi.org/10.2337/diacare.26.2007.s5) 
18 Chobanian AV, Bakris GL, Black HR, Cushman WC, Green LA, Izzo JL, Jones DW, Materson BJ, Oparil S, Wright JT, et al. The seventh report of the Joint National Committee on Prevention Detection, Evaluation, and Treatment of High Blood Pressure: the JNC 7 report. JAMA 2003289 2560-2572. (https://doi.org/10.1001/ jama.289.19.2560)

19 Lie RF, Schmitz JM, Pierre KJ \& Gochman N. Cholesterol oxidasebased determination, by continuous-flow analysis, of total and free cholesterol in serum. Clinical Chemistry 197622 1627-1630. (https:// doi.org/10.1093/clinchem/22.10.1627)

20 Lopes-Virella MF, Stone P, Ellis S \& Colwell JA. Cholesterol determination in high-density lipoproteins separated by three different methods. Clinical Chemistry 197723 882-884. (https://doi. org/10.1093/clinchem/23.5.882)

21 Fossati P \& Prencipe L. Serum triglycerides determined colorimetrically with an enzyme that produces hydrogen peroxide. Clinical Chemistry 198228 2077-2080. (https://doi.org/10.1093/ clinchem/28.10.2077)

22 Friedewald WT, Levy RI \& Fredrickson DS. Estimation of the concentration of low-density lipoprotein cholesterol in plasma, without use of the preparative ultracentrifuge. Clinical Chemistry 197218 499-502. (https://doi.org/10.1093/clinchem/18.6.499)

23 Burnett RW, D'Orazio P, Fogh-Andersen N, Kuwa K, Kulpmann WR, Larsson L, Lewnstam A, Maas AH, Mager G, Spichiger-Keller U, et al. IFCC recommendation on reporting results for blood glucose. Clinica Chimica Acta 2001307 205-209. (https://doi.org/10.1016/s00098981(01)00431-4)

24 McKenna SP, Doward LC, Alonso J, Kohlmann T, Niero M, Prieto L \& Wiren L. The QoL-AGHDA: an instrument for the assessment of quality of life in adults with growth hormone deficiency. Quality of Life Research 19998 373-383. (https://doi. org/10.1023/a:1008987922774)

25 McKenna S \& Doward L. Measuring quality of life in adults with growth hormone deficiency. Clinical Endocrinology 199645 507-508. (https://doi.org/10.1046/j.1365-2265.1996.t01-3-00826.x)

26 Speth RC, D'Ambra M, Ji H \& Sandberg K. A heartfelt message, estrogen replacement therapy: use it or lose it. American Journal of
Physiology: Heart and Circulatory Physiology 2018315 H1765-H1778. (https://doi.org/10.1152/ajpheart.00041.2018)

27 Hodis HN, Mack WJ, Henderson VW, Shoupe D, Budoff MJ, HwangLevine J, Li Y, Feng M, Dustin L, Kono N, et al. Vascular effects of early versus late postmenopausal treatment with estradiol. New England Journal of Medicine 2016374 1221-1231. (https://doi. org/10.1056/NEJMoa1505241)

28 Hodis HN \& Mack WJ. The timing hypothesis and hormone replacement therapy: a paradigm shift in the primary prevention of coronary heart disease in women. Part 2: comparative risks. Journal of the American Geriatrics Society 201361 1011-1018. (https://doi. org/10.1111/jgs.12281)

29 Hodis HN, Mack WJ, Shoupe D, Azen SP, Stanczyk FZ, HwangLevine J, Budoff MJ \& Henderson VW. Methods and baseline cardiovascular data from the early versus late intervention trial with estradiol testing the menopausal hormone timing hypothesis. Menopause 201522 391-401. (https://doi.org/10.1097/ GME.0000000000000343)

30 Zadik Z, Chalew SA, McCarter Jr RJ, Meistas M \& Kowarski AA. The influence of age on the 24-hour integrated concentration of growth hormone in normal individuals. Journal of Clinical Endocrinology and Metabolism 198560 513-516. (https://doi.org/10.1210/jcem-60-3-513)

$31 \mathrm{Xu}$ X, Bennett SA, Ingram RL \& Sonntag WE. Decreases in growth hormone receptor signal transduction contribute to the decline in insulin-like growth factor I gene expression with age. Endocrinology 1995136 4551-4557. (https://doi.org/10.1210/ endo.136.10.7664676)

32 Dehkhoda F, Lee CMM, Medina J \& Brooks AJ. The growth hormone receptor: mechanism of receptor activation, cell signaling, and physiological aspects. Frontiers in Endocrinology 20189 35. (https:// doi.org/10.3389/fendo.2018.00035)

33 Hoybye C, Burman P, Feldt-Rasmussen U, Hey-Hadavi J, Aydin F, Camacho-Hubner C \& Mattsson AF. Change in baseline characteristics over 20 years of adults with growth hormone (GH) deficiency on GH replacement therapy. European Journal of Endocrinology 2019181 629-638. (https://doi.org/10.1530/EJE-19. 0576)

Received in final form 8 June 2020

Accepted 18 June 2020

Accepted Manuscript published online 19 June 2020
This work is licensed under a Creative Commons Attribution-NonCommercial 4.0 International License. ded from Bioscientifica.com at 04/26/2023 11:47:48AM 